\title{
First Prototypes of the Superconductive Reference Device SRD1000
}

\author{
W. A. Bosch ${ }^{1}$, J. Flokstra ${ }^{2}$, G. E. de Groot ${ }^{4}$, M. J. de Groot ${ }^{3}$, R. Jochemsen ${ }^{4}$, \\ F. Mathu ${ }^{1}$, A. Peruzzi ${ }^{3}$, and D. Veldhuis ${ }^{2}$ \\ ${ }^{1}$ Hightech Development Leiden, Leiden, The Netherlands \\ ${ }^{2}$ University of Twente, Enschede, The Netherlands \\ ${ }^{3}$ NMi van Swinden Laboratorium, Delft, The Netherlands \\ ${ }^{4}$ Leids Instituut voor Onderzoek in de Natuurkunde, Leiden, The Netherlands
}

\begin{abstract}
In the framework of the European Project "Ultra-Low Temperature Dissemination (ULT)," a superconductive reference device (SRD1000) and dedicated external measurement electronics were developed to provide direct traceability to the new Provisional Low Temperature Scale (PLTS-2000). The SRD1000 includes 10 reference points in the temperature range $15 \mathrm{mK}$ to $1 \mathrm{~K}: \mathrm{W}\left(T_{C}=15 \mathrm{mK}\right)$, Be $\left(T_{C}=23 \mathrm{mK}\right), \operatorname{Ir}_{80} \mathrm{Rh}_{20}\left(T_{C} \approx 35 \mathrm{mK}\right), \operatorname{Ir}_{92} \mathrm{Rh}_{08}\left(T_{C} \approx\right.$ $65 \mathrm{mK}), \operatorname{Ir}\left(T_{C}=100 \mathrm{mK}\right), \mathrm{AuAl}_{2}\left(T_{C}=160 \mathrm{mK}\right), \operatorname{AuIn}_{2}\left(T_{C}=208 \mathrm{mK}\right), \mathrm{Cd}\left(T_{C}=520 \mathrm{mK}\right), \mathrm{Zn}\left(T_{C}=850 \mathrm{mK}\right)$ and $\mathrm{Al}\left(T_{C}=1180 \mathrm{mK}\right)$. After extensive research and development in the preparation and in the ultra-low temperature characterization of superconductive reference materials during the past years, eventually a final selection of the materials to be included in the first SRD1000 prototype sensors was made. In this paper, the superconducting transitions observed for the selected materials and the sample preparations are reported, the SRD1000 sensor and external electronics technology are described with some detail, and the ULT facility set up to calibrate the prototype sensors and the future commercial devices is presented.
\end{abstract}

\section{INTRODUCTION}

The request from the low temperature research community for accurate and traceable temperature measurements below $1 \mathrm{~K}$ has led recently to the adoption of a provisional extension of the ITS-90 from $0.9 \mathrm{mK}$ to $1 \mathrm{~K}$ (Provisional Low Temperature Scale, PLTS-2000) [1]. The melting pressure of ${ }^{3} \mathrm{He}$ was selected as the carrier of the PLTS-2000, and the scale was defined by an internationally accepted equation relating the ${ }^{3} \mathrm{He}$ melting pressure to temperature. The practical realization of the PLTS2000 requires a ${ }^{3} \mathrm{He}$ melting curve thermometer (MCT) to be set up and to be operated [2]: both matters are expensive, time consuming and demand highly experienced personnel. As a consequence, the MCT and the PLTS-2000 that can be generated with it are still confined to a few national metrology institutes and are not accessible to the majority of the users.
Superconductive temperature reference points have proved to be a very useful and accurate direct means of providing traceable thermometry below $1 \mathrm{~K}$. Two different superconductive reference point devices (SRM 767 [3, 4] and SRM 768 [5]), developed and commercialized by the National Institute of Standards and Technology (NIST, USA), were widely employed in the past and they are still employed to transfer information between the different realizations of ultra-low temperature scales. Unfortunately the production of the NIST devices was discontinued. Further metrological investigations on high-purity superconductors [6] showed that highly reproducible superconductive reference points can be realized with high-purity metals by applying convenient methods for sample preparation and characterization.

There are two intrinsic aspects, to be taken into account when the superconductive transitions are used as temperature reference: 
1. There is no latent heat involved in the transition so that the temperature must be controlled externally (while an ordinary fixed point like a triple point or a freezing point is a "self-controlling temperature generator”).

2. The temperature transition is so sensitive to impurities, crystal defects and stresses that it is not possible to prepare samples that show identical (within a few tenths of a millikelvin) transition temperatures even when each specimen is prepared starting from the same bulk material and adopting the same preparation method. Therefore each sample must be calibrated individually.

To provide a direct and accurate traceability to the PLTS-2000, a Dutch consortium of research institutes and industries developed a new superconductive reference device (SRD1000) [7-9]. The SRD1000 includes 10 superconductive temperature reference points in the temperature range $10 \mathrm{mK}$ to $1 \mathrm{~K}$ and dedicated room-temperature measurement electronics.

In this paper we report on the final selection of the materials and the preparation of the samples to be included in the first prototype devices, we describe with some detail the planar microcoil sensor and the external detection system. Finally the ULT facility, set up to calibrate the prototype sensors and the future commercial devices, is presented.

\section{SELECTION OF THE REFERENCE MATERIALS}

We prepared, shaped and tested several batches of reference materials. The analysis of the results led us to the final selection of the materials to be included in the first prototype devices of SRD1000. Table 1 shows the materials selected for the SRD1000 prototypes, the preparation and specification of samples, the observed transition temperature $T_{C}$, the observed transition width $W$, and the related repeatability of $T_{C}$ within the same run (the repeatability of a transition is $12.5 \%$ of the transition width, assuming that the repeatability of the transition midpoint is $10 \%$ of the voltage step corresponding to the complete transition). The $W$ in typical SRM 767 and 768 devices [4, 5] is listed as well.
For all the samples (except for $\mathrm{Cd}$ and $\mathrm{Zn}$ ) the repeatablity obtained is better than the standard uncertainty of the PLTS-2000 in thermodynamic terms $(0.5 \mathrm{mK}$ down to $500 \mathrm{mK}, 0.2 \mathrm{mK}$ at $100 \mathrm{mK}$ and $0.3 \%$ of $T$ at $25 \mathrm{mK})$.

In Figures 1 (where, for comparison, also our NIST SRM 768 tungsten is shown), 2, 3 and 4 the transitions observed for respectively $\mathrm{W}, \mathrm{Be}, \mathrm{Ir}_{80} \mathrm{Rh}_{20}$ and $\mathrm{Al}$ are shown. The residual slope in the output signal outside the transition range, which does not allow an unambiguous definition of $T_{C}$ (see the SRM $768 \mathrm{~W})$, is absent in the SRD1000.

\section{THE SRD1000 SENSOR AND ELECTRONICS}

The SRD1000 sensor is shown in Figure 5. The sensor is thermally connected to the experimental region of a cryogenic cooling system for thermometry measurements. The SRD1000 uses a mutual inductance system consisting of planar niobium micro-coils (a1) to detect the superconducting to normal transitions of the reference samples. The samples are directly attached to this detecting system (a2). The detector and samples are thermally connected to a gold-plated copper holder (b1 is without and b2 is with detector). The geometry of the planar coil system allows miniaturization of the total SRD1000 sensor. The sensor may hold up to 12 reference samples and an optional CMN thermometer in a volume of less than $\varnothing 10 \mathrm{~mm}$ and $50 \mathrm{~mm}$ length. Furthermore the planar detector behaves like an ideal mutual inductance with minimal coupling to the copper holder, resulting in a sensor output which does not depend on temperature at temperatures between the reference points. The geometry also allows a short thermal path between the samples and copper holder. A magnetic shield (c) surrounds the copper holder, consisting of a Cryoperm outer shield and a niobium inner shield. It reduces ambient magnetic fields by a factor of 500 or more. 


\begin{tabular}{|c|c|c|c|c|c|}
\hline $\begin{array}{l}\text { Selected } \\
\text { Material }\end{array}$ & Specification and preparation & $\begin{array}{c}\text { Observed } \\
T_{C} \\
{[\mathbf{m K}]} \\
\end{array}$ & $\begin{array}{c}\text { Observed } \\
W \\
{[\mathrm{mK}]} \\
\end{array}$ & $\begin{array}{c}\Delta T_{C} / T_{C} \\
{[\%]}\end{array}$ & $\begin{array}{c}\text { Typical } W \text { in } \\
\text { SRM } 767 / 768 \\
{[\mathrm{mK}]} \\
\end{array}$ \\
\hline $\mathrm{W}$ & $\begin{array}{l}4 \mathrm{~N} \text { single crystal }{ }^{1)} \text { spark cut to } 3 \times 3 \times 0.2 \\
\text { mm sample, all sides polished and } \\
\text { rounded off, Al spot weld on top of } \\
\text { sample to reduce supercooling, } \\
\text { ultrasonically cleaned in acetone and } \\
\text { alcohol }\end{array}$ & 15 & 0.1 & 0.08 & 0.7 \\
\hline $\mathrm{Be}$ & $\begin{array}{l}\text { 2N8 foil }{ }^{2)} \text { sheet cut to } 3 \times 3 \mathrm{~mm} \text { sample, } \\
\text { ultrasonically cleaned in acetone and } \\
\text { alcohol, Al spot weld on top of sample } \\
\text { to reduce supercooling }\end{array}$ & 22 & 0.3 & 0.17 & 0.2 \\
\hline $\mathrm{Ir}_{80} \mathrm{Rh}_{20}$ & \multirow{2}{*}{$\begin{array}{l}\text { 4N5 Ir powder }{ }^{2)} \text { and } 4 \mathrm{~N} \text { Rh powder }{ }^{2)} \\
\text { mixed to proper ratio, arc melted to } \\
\text { form droplet-shaped sample, annealed } \\
\text { for one week in arc melt furnace close } \\
\text { to melting point, spark cut to } 3 \times 3 \times 0.5 \\
\text { mm sample, all sides polished and } \\
\text { rounded off, ultrasonically cleaned in } \\
\text { acetone and alcohol }\end{array}$} & 34 & 0.3 & 0.11 & - \\
\hline $\mathrm{Ir}_{92} \mathrm{Rh}_{08}$ & & 65 & 1.2 & 0.22 & - \\
\hline Ir & $\begin{array}{l}\text { melt } 4 \text { N5 Ir powder }{ }^{2} \text { to form droplet } \\
\text { shaped sample, spark cut to } 3 \times 3 \times 0.5 \\
\text { mm sample, all sides polished and } \\
\text { rounded off, ultrasonically cleaned in } \\
\text { acetone and alcohol }\end{array}$ & 100 & 0.5 & 0.06 & 0.8 \\
\hline $\mathrm{AuAl}_{2}$ & $\begin{array}{l}5 \mathrm{~N} 4 \mathrm{Au} \text { powder }{ }^{2} \text { and } 5 \mathrm{~N} \mathrm{Al} \text { powder } \\
\text { arc melted to form a seed crystal, } \\
\text { single crystal is grown in tri-arc furnace } \\
\text { using seed crystal, spark cut to } 3 \times 3 \times 0.5 \\
\text { mm sample, all sides polished and } \\
\text { rounded off, ultrasonically cleaned in } \\
\text { acetone and alcohol }\end{array}$ & 161 & 0.2 & 0.02 & 0.3 \\
\hline $\mathrm{AuIn}_{2}$ & $\begin{array}{l}6 \mathrm{~N} \mathrm{Au} \mathrm{powder}{ }^{3)} \text { and } 6 \mathrm{~N} \text { In powder }{ }^{4)} \mathrm{Au} \\
\text { arc melted to form a seed crystal, } \\
\text { single crystal is grown in tri-arc furnace } \\
\text { using seed crystal, spark cut to } 3 \times 3 \times 0.5 \\
\text { mm sample, all sides polished and } \\
\text { rounded off, ultrasonically cleaned in } \\
\text { acetone and alcohol }\end{array}$ & 208 & 0.4 & 0.02 & 0.4 \\
\hline $\mathrm{Cd}$ & $\begin{array}{l}6 \mathrm{~N} \mathrm{shot}^{2)} \text { melted and annealed to single } \\
\text { crystal, spark cut to } 3 \times 3 \times 0.2 \mathrm{~mm} \\
\text { sample, ultrasonically cleaned in } \\
\text { acetone and alcohol }\end{array}$ & 520 & 4.5 & 0.11 & 2.5 \\
\hline $\mathrm{Zn}$ & $\begin{array}{l}6 \mathrm{~N} \text { shot }^{3)} \text { melted and annealed to single } \\
\text { crystal, spark cut to } 3 \times 3 \times 0.2 \mathrm{~mm} \\
\text { sample, ultrasonically cleaned in } \\
\text { acetone and alcohol }\end{array}$ & 850 & 11 & 0.16 & 8.4 \\
\hline $\mathrm{Al}$ & $\begin{array}{l}5 \mathrm{~N} 5 \text { foil }^{2)} \text { sample cut to } 3 \times 3 \mathrm{~mm} \text {, } \\
\text { ultrasonically cleaned in acetone and } \\
\text { alcohol }\end{array}$ & 1182 & 3.5 & 0.04 & 2.6 \\
\hline
\end{tabular}

\footnotetext{
1) Goodfellow, 4N refers to 99.99 \% nominal purity; ${ }^{2)}$ Alfa Aesar, ${ }^{3)}$ Cominco, ${ }^{4)}$ Kawecki Biliton
} 

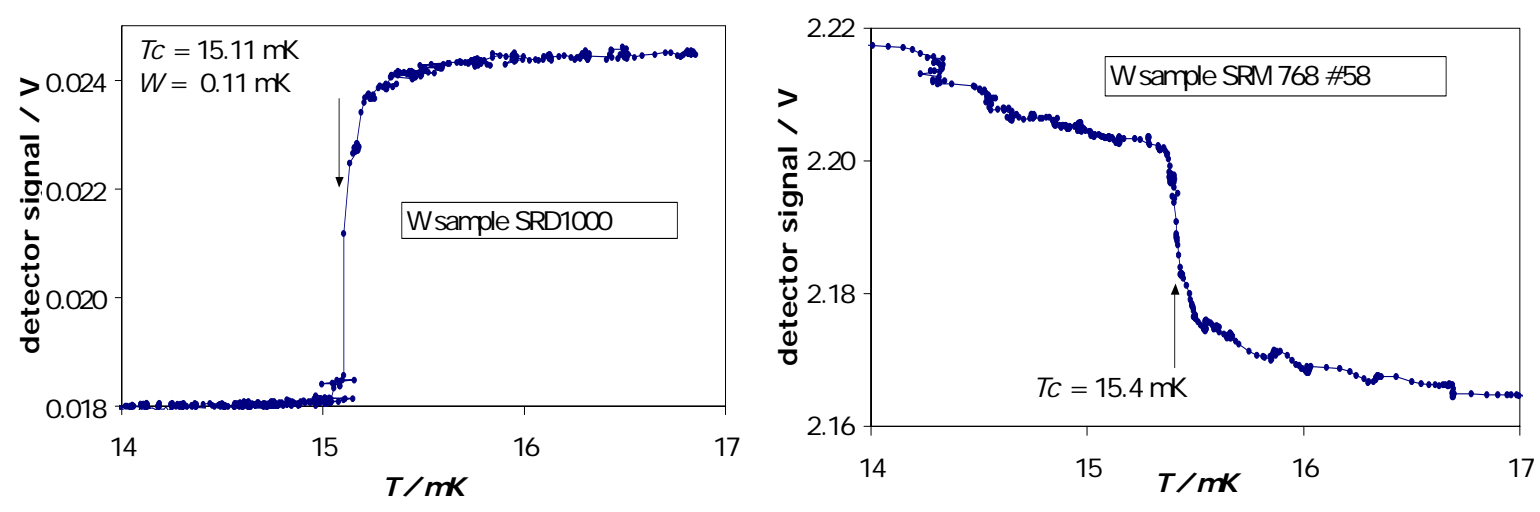

FIGURE 1. a) Transition of an SRD1000 W sample and b) transition of an SRM768 \#58 W sample.

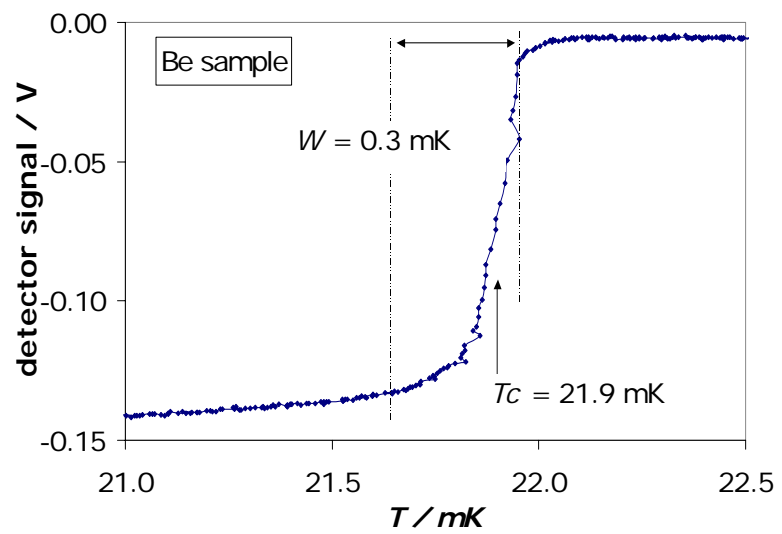

FIGURE 2. Transition of a Be sample.

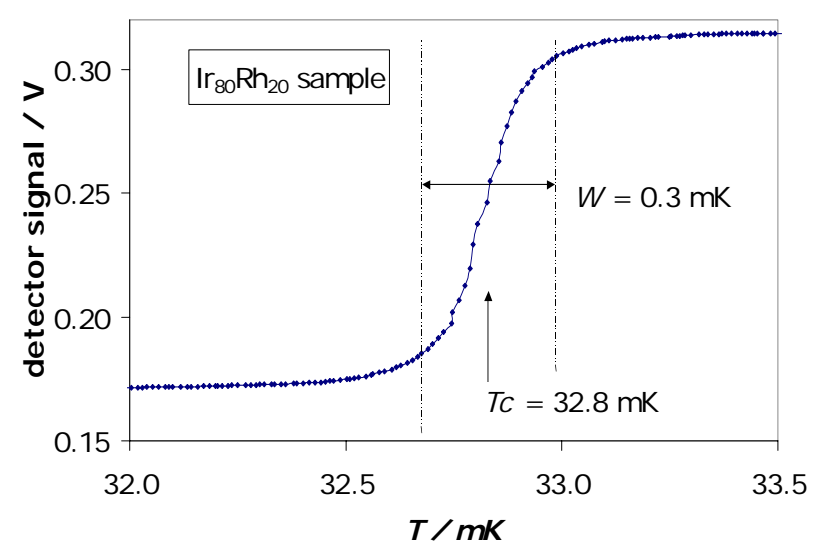

FIGURE 3. Transition of an $\operatorname{Ir}_{80} \mathrm{Rh}_{20}$ sample.

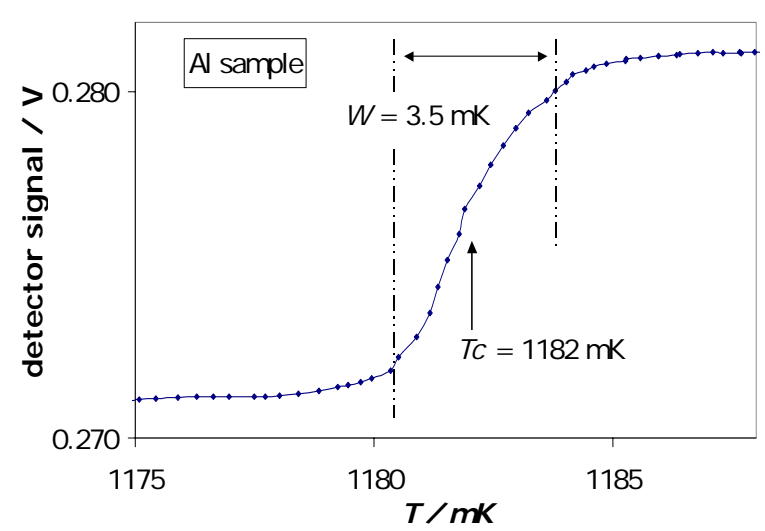

FIGURE 4. Transition of an $\mathrm{Al}$ sample.

Figure 6 shows the main unit of the dedicated room-temperature electronics to measure the mutual inductance of the SRD1000 sensor. A primary AC current of $50 \mu \mathrm{A}$ and $976 \mathrm{~Hz}$ is applied to the sensor, providing an AC measurement field of about $0.2 \mu \mathrm{T}$ at the samples.

The electronics provides a DC output signal proportional to the mutual inductance of the sensor; see Figure 7. The steps in the staircase function shown in the figure are located at the SRD1000 transition temperatures. For intermediate temperatures the output voltage level indicates the temperature area of the sensor. The circuitries of the current source, amplifiers and AC detector of the electronics are balanced and designed for ultra-low noise operation, enabling a high stability of the output signal (better than $50 \mathrm{ppm} /{ }^{\circ} \mathrm{C}$ ) and an excellent immunity from external interferences. 
The signal to noise ratio ranges from about 30 for the W transition to about 400 for the Be transition.

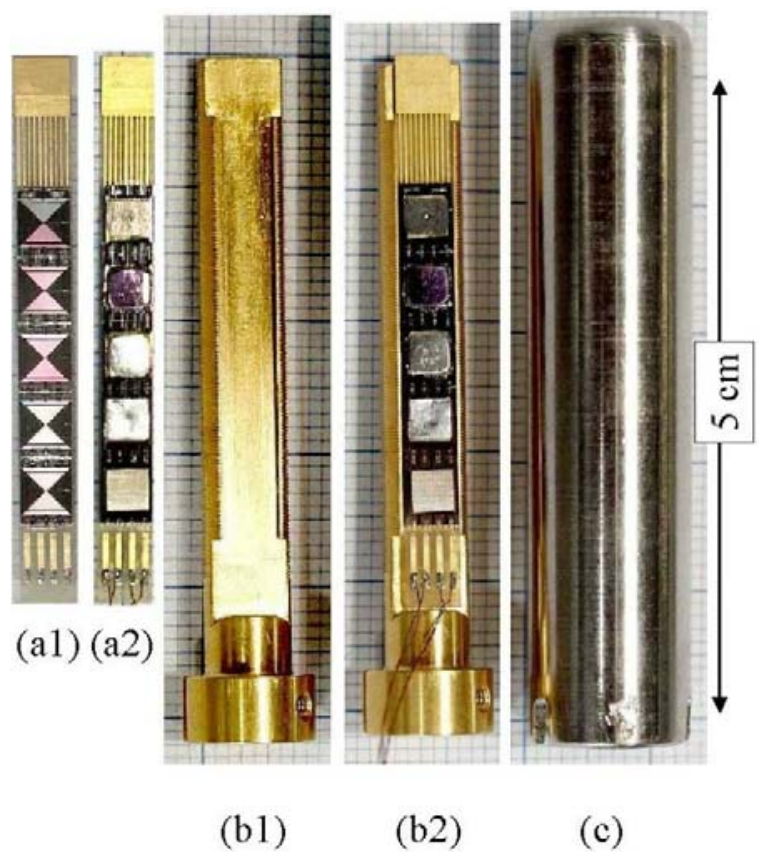

FIGURE 5. SRD1000 sensor consists of two planar detector systems (a1); on each detector five samples are attached (a2); a gold plated copper holder (b1) carries the detector systems (b2); and magnetic shielding surrounds the copper holder (c).

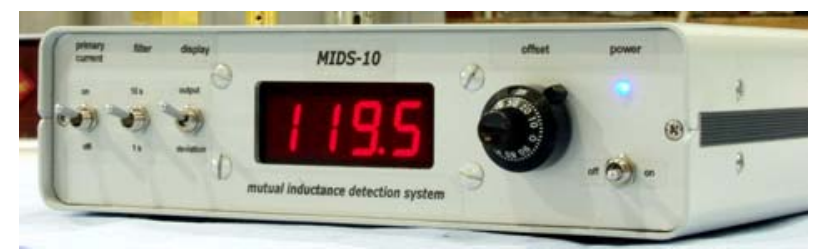

FIGURE 6. The MIDS-10 main unit of the SRD1000 electronics.

\section{RESIDUAL MAGNETIC FIELDS}

A check of the residual magnetic field can be performed by using an additional coil (also included in the device) in the following way: the temperature is controlled at the midpoint of a superconductive transition, and DC currents of opposite sign are sent to the additional coil that shift the transition. Provided the same transition has been previously observed, the temperature-transition shift and the residual field (the axial component) can be derived from the output voltage change induced by the added currents. The shift in the transition temperature due to the residual field was always found to be lower than $0.02 \mathrm{mK}$.

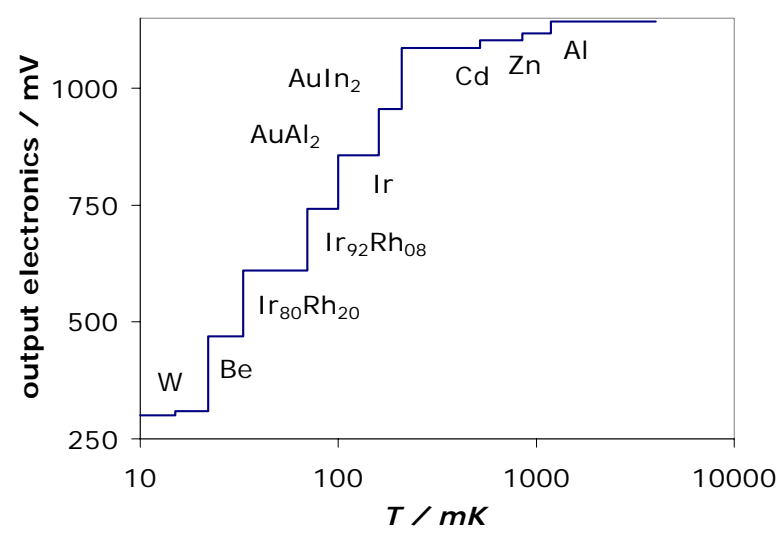

FIGURE 7. Output signal of the SRD1000 electronics as a function of temperature.

\section{CALIBRATION FACILITY AND PROCEDURE}

A gold-plated copper comparator block is attached to the mixing-chamber stage of an Oxford Instruments Kelvinox $400{ }^{3} \mathrm{He}-{ }^{4} \mathrm{He}$ dilution refrigerator. On the copper comparator block the following elements are attached : a ${ }^{3} \mathrm{He}$ MCT cell (PTB design, see ref. [2]), an SRM768 device, an SRM767 device, up to four SRD1000 prototype devices, a RhFe standard thermometer (Tinsley 223687, calibrated at NMi in terms of ITS-90), a $\mathrm{RuO}_{2}$ thermometer and a Speer Carbon thermometer.

After the formation of the ${ }^{3} \mathrm{He}$ solid plug along the filling capillary, the pressure sensor of the ${ }^{3} \mathrm{He}$ MCT cell is calibrated at the minimum of the ${ }^{3} \mathrm{He}$ melting curve and at the 5 superconductive reference points provided by SRM 768 (\# 58, recently calibrated by PTB). A linear relation between $p$ and $1 / C$ is adopted and no correction is applied for the non-linearity of the sensor, as it is estimated to be lower than $100 \mathrm{~Pa}$ for any pressure value in the ${ }^{3} \mathrm{He}$ melting range (lower than $0.04 \mathrm{mK}$ in temperature).

The calibration of the SRD1000 prototypes is based on the PLTS-2000 (by direct use of the MCT) up to the Cd samples and on the ITS-90 (by using the 
calibrated RhFe standard thermometer) for the $\mathrm{Zn}$ and Al samples.

During the calibration of the SRD1000 prototypes, the temperature is swept in steps, allowing all the different elements mounted on the comparator block to reach thermal equilibrium after each step. The temperature steps are selected in order to have at least 10 equilibrium points along the sensitive part (10\% to $90 \%$ ) of the superconductive transition.

\section{FUTURE DEVELOPMENTS}

Five prototypes are currently being assembled and calibrated. Next the prototypes will be metrologically evaluated by the other European partners of the project: the transition temperatures on the PLTS-2000 will be found, the width and repeatability of the superconductive transitions will be determined and the effects of thermal and measuring parameters will be finalized.

\section{CONCLUSION}

A new superconductive reference device was developed to provide direct and accurate traceability to the PLTS-2000. The results obtained on the samples selected showed that the SRD1000 can fill the vacancy left by NIST after discontinuing the production of the SRM 768. After the evaluation performed by the other European partners, the commercial production of calibrated devices will start. The inclusion of a magnetic thermometer (CMN) to interpolate between the reference point will be considered.

\section{ACKNOWLEDGMENTS}

This work is partially funded by the European Commission under the Measurement and Testing activity of the Programme for Competitive and Sustainable Growth, contract no. G6RD-CT-199900119.

\section{REFERENCES}

1. Bureau international des poids et mesures, Comité Consultatif de Thermometrie (CCT), "Working Group 4 Report to CCT,” Document CCT/2000-26, April 2000.

2. Hoffmann, A., and Shuster, G., "Design aids for the operating system of a ${ }^{3} \mathrm{He}$ melting curve thermometer," in Progress Report European Ultra-Low Temperature Scale and Traceability, contract SMT4-CT96-2052, November 1996.

3. Schooley, J. F., Soulen, R. J. Jr, and Evans, G. A. Jr, Standard Reference Materials: Preparation and Use of Superconductive Fixed-Point Devices, SRM 767, NBS Special Publication 260-44, 1972, pp. 1-35.

4. Soulen, R. J. Jr, and Dove, R. B., SRM 768: Temperature Reference Standard for Use below 0.5 K, NBS Special Publication 260-62, U. S. Govt. Printing Office, Washington, D. C., 1979, pp. 1-37.

5. El Samahay, A. E., Durieux, M., Rusby, R. L., Kemp, R. C., and Kemp, R. G., "Realizations of the Superconductive Transition Points of Lead, Indium, Aluminium, Zinc and Cadmium with SRM 767 Devices," in Temperature: Its Measurement and Control in Science and Industry, edited by J. F. Schooley, AIP, New York, 1982, 5, pp. 261-265.

6. Fellmuth, B., "Temperature Fixed-point using Highpurity Superconductors," in Temperature: Its Measurement and Control in Science and Industry, edited by J. F. Schooley, AIP, New York, 1992, 6, pp. 233-238.

7. Bosch, W. A., Chinchure, A., Flokstra, J., de Groot, M. J., van Heumen, E., Jochemsen, R., Mathu, F., Peruzzi, A., and Veldhuis, D., "Status Report on the Development of a Superconductive Reference Device for Precision Thermometry below $1 \mathrm{~K}$," in Proceedings of the $8^{\text {th }}$ International Symposium on Temperature and Thermal Measurements in Industry and Science (TEMPMEKO2001), edited by B. Fellmuth et al., VDE Verlag, Berlin, 2001, pp. 397-401.

8. Storm, A. J., Bosch, W. A., de Groot, M. J., Jochemsen, R., Mathu, F., and Nieuwenhuis, G. J., in Proceedings of the $7^{\text {th }}$ International Symposium on Temperature and Thermal Measurements (TEMPMEKO99), edited by J. Dubbeldam et al., NMi van Swinden Laboratorium, Delft, 1999, pp. 142-146.

9. Hightech Development Leiden, Leiden, The Netherlands, e-mail: HDLinfo@xs4all.nl. 